\title{
El Levantamiento de los Libres del Sur (1839): un abordaje desde el estudio de redes*
}

\author{
The Uprising of the Libres del Sur (1839): A Network Analysis Approach
}

\author{
CAROLINA GERMINARIO
}

\section{Resumen}

El objetivo de este trabajo es realizar un ejercicio metodológico desde la perspectiva de redes sociales que permita visualizar las posibles relaciones familiares, comerciales, de amistad, laborales, entre los principales líderes del Levantamiento de los Libres del Sur, ocurrido en la campaña sur de Buenos Aires en 1839. A partir de la identificación y caracterización de un sujeto que es central para el Levantamiento, Ambrosio Crámer, intentamos reconstruir las trayectorias de los demás participantes y sus vínculos. A partir de un recorrido historiográfico, histórico y metodológico que integra bibliografía y fuentes buscamos indagar sobre las posibilidades del estudio de redes para una coyuntura de crisis.

Palabras clave

Campaña; Análisis de Redes; Levantamiento; Rosas.

\begin{abstract}
The purpose of this paper is to carry out a methodological exercise from the perspective of social network analysis. This approach allows us to visualize the possible family, commercial, friendship and labor relationships among the main leaders of the Uprising of the Libres del Sur, which took place in the southern campaign of Buenos Aires in 1839. From the identification and characterization of a subject which is essential for the Uprising, Ambrosio Crámer, we try to reconstruct the trajectories of the other participants and their connections. From a historiographic, historical and methodological journey that integrates bibliography and documents we explore the possibilities of the network analysis for a critical time.
\end{abstract}

Keywords

Campaign; Network Analysis; Uprising; Rosas.

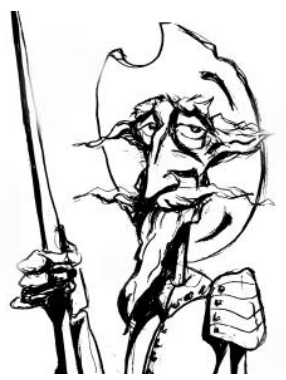

Recibido con pedido de publicación el 4 de febrero de 2021

Aceptado para su publicación el 13 de julio de 2021

Versión definitiva recibida el 12 de noviembre de 2021

https://doi.org/10.35305/prohistoria.vi36.1517

Carolina Germinario, Grupo de Investigación en Historia Americana, Centro de Estudios Históricos, Facultad de Humanidades, Universidad Nacional de Mar del Plata, Mar del Plata, Argentina; e-mail: caro.germinario@gmail.com

\footnotetext{
* Agradecemos especialmente a los revisores anónimos de la revista que realizaron comentarios, aportes y sugerencias muy enriquecedoras.

Esta obra se publica bajo licencia Creative Commons. Atribución-NoComercial-CompartirIgual 4.0 Internacional

Germinario, C. El Levantamiento de los Libres del Sur (1839): un abordaje desde el estudio de redes. Prohistoria, Año XXIV, 36, dic. 2021, 1-31. 


\section{Introducción}

El Levantamiento de los Libres del Sur tuvo lugar en 1839 en la campaña de Buenos Aires. Un grupo de vecinos de Dolores y alrededores se reunieron en la plaza pública para manifestar su oposición al Gobernador de Buenos Aires, Juan Manuel de Rosas, y desplazar al Juez de Paz para nombrar uno afín a sus intereses. En un lapso de diez días aproximadamente, entre fines de octubre y comienzos de noviembre, desde Monsalvo, pasando por Tandil y confluyendo en Chascomús diferentes partidas armadas se fueron armando para la batalla definitiva. En ella, las fuerzas rosistas organizadas por el hermano del Gobernador, Prudencio Rosas en conjunto con Nicolás Granada, Vicente González y con el apoyo de algunos grupos de indios amigos, derrotaron a los rebeldes. Esto no significó el fin de la conmoción en el entorno rural de Buenos Aires. Durante varios meses perduraron los conflictos, pequeños enfrentamientos y desconfianzas.

El objetivo de este trabajo es realizar un primer ejercicio metodológico desde la perspectiva de redes sociales que permita visualizar las posibles relaciones familiares, comerciales, de amistad, laborales, entre los principales líderes de la sublevación. A partir de la identificación y caracterización de un sujeto que es central para el Levantamiento, Ambrosio Crámer, intentamos reconstruir las trayectorias de los demás participantes y sus conexiones. ${ }^{1} \mathrm{El}$ trabajo lo organizamos de la siguiente manera: en un primer apartado, una breve recuperación de los principales preceptos de la investigación en redes sociales; en segundo lugar, presentamos algunas premisas historiográficas sobre la campaña de Buenos Aires y la provincia hacia 1839 que permiten comprender el marco en el cual ocurre el Levantamiento; en tercer lugar presentamos la información relevada sobre las trayectorias de los líderes de la sublevación y luego al sujeto elegido como centro de la red, Ambrosio Crámer y su rol en la acción; y, por último, un balance sobre el ejercicio realizado y reflexiones posibles.

\section{El estudio de las redes sociales: aportes y enfoques}

El corpus historiográfico que nos permite realizar este ejercicio se enmarca en las investigaciones generales sobre las formas que tomó la transición del Antiguo Régimen a un orden post revolucionario basado en la soberanía y la representación. Dentro de este problema se destacan las investigaciones que se enfocan en la política, que experimentaron a su vez una revitalización al recuperar e integrar los aportes de otras disciplinas sociales y humanísticas (Hespanha, 1996; Morelli, 2007; Palti, 2007). Las principales contribuciones

\footnotetext{
${ }^{1}$ El objetivo específico de este trabajo forma parte de la investigación en curso que estamos realizando gracias a la beca tipo A de la Universidad Nacional de Mar del Plata.
} 
provenientes de la historia política radican en una mejor comprensión de los mecanismos que fueron pilares para la construcción de las lógicas de poder local y global entre el orden tardo-colonial y la conformación de los Estados Nacionales en la segunda mitad del siglo XIX (Garavaglia, 2007). Estos estudios habilitan la visualización y reconstrucción de las redes de relaciones familiares, sociales y comerciales y su circulación en diferentes escalas, evidenciando cómo las estrategias de los actores son transversales y se reformulan en función de los cambios políticos y económicos (Bertrand, 2000; Caula, 2013; Gelman, 1996; Moutoukias, 1996). Los estudios sobre redes de relaciones integran múltiples conceptualizaciones y enfoques. En este trabajo tomamos los aportes de "network analysis" o "análisis de redes sociales" que consisten en la reconstrucción y análisis de redes, entendiéndolas como un conjunto de relaciones entre individuos $y$, en el caso particular, de un personaje determinado en un período o momento histórico (Imízcoz Beunza, 2009: 77).

Los estudios de redes aplicados al periodo monárquico y postrevolucionario han mostrado cómo la participación en distintas instancias administrativas e institucionales garantizaba la integración de los agentes en las estructuras locales del poder imperial, lo cual les permitía ampliar las conexiones, obtener prestigio y buenos negocios. Los tejidos sociales del comercio y la política se confundían en una única trama de relaciones (Moutoukias, 2000: 408). Estas redes vinculares no se interrumpieron con el proceso revolucionario, por el contrario, se vieron reformuladas y resignificadas (Molina, 2011; Moutoukias, 2015; Valle \& Larrosa, 2019).

Otro aspecto teórico del enfoque de redes tiene que ver con la categorización de los vínculos posibles de un sujeto. En primer lugar, se encuentran los vínculos de parentesco, familiares y matrimoniales, cuya relevancia era central en el Antiguo Régimen y también a lo largo del siglo XIX (Hora \& Losada, 2015; Socolow, 1991). Luego las conexiones vinculadas a la amistad y el patronazgo (Santilli, 2003), en este grupo se integran también aquellas relaciones nacidas en instancias formativas (Imízcoz Beunza, 2009: 91). Es en este sentido que, al identificar las trayectorias pasadas de varios sujetos intervinientes en el Levantamiento, encontramos que en algunos casos pertenecen a familias con anclaje virreinal. A su vez, detectamos vínculos de amistad forjados al calor de las armas en los tiempos de las guerras de independencia que, como ya se ha trabajado, fueron experiencias conformadoras de identidad (Bragoni \& Mata de López, 2007; Parrado, 2020).

Un elemento central de los análisis de redes sociales son las fuentes. La fuente por excelencia es la correspondencia epistolar. Pero, además de ellas, puede utilizarse cualquier tipo de documentación que exponga a un individuo en su vida en sociedad: registros parroquiales, testamentos, registros matrimoniales, transacciones comerciales. En síntesis, documentación judicial, 
civil y eclesiástica, sumada a producción autobiográfica si hubiere. Por último, nos resulta central realizar algunas consideraciones. Si bien los vínculos se dan y perduran a lo largo del tiempo, conviene tener presentes las salvedades que Moutoukias ha hecho sobre el rol de la incertidumbre y el conflicto en los vínculos, ateniendo a que "los lazos sociales no son algo fijo, sustantivo o preestablecido, sino que se construyen en la acción" (Imízcoz Beunza, 2009: 96). ${ }^{2}$ Esta afirmación nos resulta central para este trabajo ya que, como mencionamos al comienzo, lo que nos interesa es indagar sobre los vínculos que se forjaron en función del Levantamiento y los orígenes de esas redes. En este trabajo tenemos la dificultad de carecer de fuentes primarias pertenecientes directamente a los sujetos en cuestión. Por este motivo, en primer lugar, este es un ejercicio metodológico inicial que tiene como finalidad explorar si este tipo de análisis puede ser utilizado para un momento histórico puntual. En segundo lugar, disponemos de fuentes (primarias y secundarias) que nos permiten constatar que los sujetos efectivamente se conocían entre sí y algunos indicios sobre la fundamentación de esa relación. En tercer lugar, resulta importante recuperar brevemente el contexto en el que la sublevación ocurre ya que explica en gran parte las motivaciones que impulsaron a los actores a participar en ella.

\section{La campaña sur de Buenos Aires hacia 1839}

El abordaje historiográfico del ámbito rural experimenta desde las últimas décadas del siglo $\mathrm{XX}$ un crecimiento exponencial. Como punto de partida, podemos decir que se construyó una imagen renovada de la campaña de Buenos Aires entre el período tardo-colonial y mediados del siglo XIX, al asociar diferentes miradas. A través de las perspectivas económicas y sociodemográficas, se redefinen las características del poblamiento, ocupación y explotación de este espacio. Este enfoque se complementa con el examen de las prácticas y experiencias cotidianas de los actores.

A partir del aspecto socio-económico, las pesquisas sobre la campaña rural bonaerense generan un nuevo consenso, nutrido por el análisis de la diversidad de las unidades productivas, la composición sociodemográfica y las formas heterogéneas de acceso, ocupación, usufructo y/o propiedad de la tierra. La base de este acuerdo radica en que la campaña estaba poblada por múltiples actores. Pequeños y medianos productores, ocupantes y propietarios que convivían (no sin tensiones) con los grandes estancieros y practicaban diferentes formas de ocupación y usufructo de la tierra. Desde lo micro y local, diversos investigadores focalizan en las dinámicas de interacción $\mathrm{y}$

\footnotetext{
${ }^{2}$ Imízcoz Beunza cita las críticas que Zacarías Moutoukias ha hecho en diversos trabajos a los enfoques de vínculos sociales que parten de una ritualización de los mismos, dejando de lado la observación directa sobre las relaciones, excluyendo así la incertidumbre y los márgenes de libertad de los actores (Imízcoz Beunza, 2009: 96).
} 
reconstruyen las formas de vivir y trabajar de los habitantes. Asimismo, los estudios sobre las áreas de fronteras con los pueblos originarios muestran cómo el espacio considerado fronterizo, lejos de ser una línea divisoria, se constituyó como área de intercambios y negociaciones, no sólo económicos sino también sociales y culturales desde tiempos imperiales (Lanteri \& Pedrotta, 2015; Ratto, 2015; Truchuelo García \& Reitano, 2017).

La visibilización de la multiplicidad de actores, sumada al cambio de enfoque de la historia política, favoreció una revisión de cómo éstos intervinieron en los sucesos que se desencadenaron a comienzos del siglo XIX. Las investigaciones nos muestran que además de las transformaciones sociales y económicas, la década revolucionaria también trastocó las dinámicas de participación y acción de los actores. Esto supuso una politización que se plasmó primero en una movilización y militarización de los sectores urbanos con las Invasiones Inglesas, que perduró durante toda la década de 1810 (Di Meglio, 2006; Sábato \& Lettieri, 2003). Y luego, en un activo accionar político y militar de los pobladores de la campaña que se acrecentó hacia los años 1820 (Fradkin, 2006; Fradkin \& Gelman, 2008; González Bernaldo de Quirós, 1987). Tomar como premisa la ruralización de las bases de poder ${ }^{3}$ involucra observar la confluencia de dos procesos estrechamente vinculados. Por un lado, el progresivo vuelco económico de las elites comerciales de Buenos Aires a la tierra como consecuencia, en parte, de la Revolución (Irigoin \& Schmit, 2003). Por otro, al creciente peso en las decisiones políticas de los diferentes actores que habitaban la campaña. Este espacio se convirtió en un foco productivomercantil y de poder político de gran relevancia, marcado por un crecimiento constante.

Estas premisas historiográficas revelan como las prácticas y las conflictividades rurales estaban asociadas a las innovaciones productivas y económicas que ponían en tensión las formas de habitar y usufructuar la tierra que perduraban desde tiempos coloniales. Y, también, a los cambios de índole institucional y jurídica propiciados por la Revolución y luego por los intentos de construcción de un nuevo orden. Los diálogos favorecidos entre los diferentes enfoques historiográficos evidencian que la ruralización de las bases de poder y de la política se expresó a través de la participación de actores diversos. Esto nos invita a buscar un mejor conocimiento de cómo quienes habitaban la ciudad y la campaña desarrollaron diferentes estrategias y acciones de negociación o enfrentamiento ante los conflictos y situaciones que se manifestaron a escala local y regional.

\footnotetext{
${ }^{3}$ La ruralización de las bases de poder como consecuencia de la Revolución es planteada por Halperín Donghi (2014) [1972] en el libro Revolución y Guerra. Formación de una elite dirigente en la Argentina criolla, complejizada por otros autores a partir de estudios más recientes.
} 
Los años 1838-1841, fueron interpretados tradicionalmente desde el foco de las luchas facciosas entre unitarios y federales (Levene, 1940; Rosa, 1962; Saldías, 1892). Más recientemente, se conciben de manera articulada diferentes aspectos de esta coyuntura de crisis. En primer lugar, los problemas económicos desencadenados por el bloqueo francés que se entienden observando el contexto regional. En segundo lugar, la importancia de las luchas facciosas entre unitarios y federales, con los intentos de Lavalle de desestabilizar a Rosas. Tercero, el Levantamiento como la expresión de la crisis económica que evidencia las dificultades de instalar un orden legítimo y estable en la campaña sur bonaerense (Gelman, 2009). A su vez, se contemplan sus consecuencias, como fueron los embargos (Gelman \& Schroeder, 2003) las donaciones y premios de tierras (Barcos \& Lanteri, 2013; Infesta \& Valencia, 2018) y más recientemente problematizamos el análisis de la implementación de mecanismos nuevos de control orientados a reformular la organización administrativa de la campaña de Buenos Aires (Germinario, 2017, 2020).

El Levantamiento de los Libres del Sur fue una rebelión contra el rosismo liderada principalmente por estancieros y notables que tenían prestigio social e importancia económica, en su mayoría considerados federales leales al régimen. Fue leído por los contemporáneos como una traición a Rosas llevada adelante por falsos federales, que aprovecharon la crítica coyuntura económica para mostrar su verdadera faceta unitaria. Los últimos abordajes, desde una perspectiva económico-social, adjudican las causas a los conflictos económicos y políticos desencadenados tras el bloqueo del puerto y las medidas tomadas por la provincia a fin de mejorar sus finanzas (Gelman, 2009). Aun así, pese a estas contribuciones, el trasfondo de las interacciones entre los actores en su dimensión local y relacional quedaron en un lugar secundario. Ante esta constatación, nuestro análisis parte de la afirmación, sustentada en la historiografía, de que la campaña era un ámbito diverso y con dinámicas propias. El espacio geográfico, productivo y social de los partidos de Dolores y Monsalvo, focos de la rebelión, estaba ocupado por una diversidad de actores. Estancieros, arrendatarios, pobladores, comerciantes, articuladores del poder provincial como los Jueces de Paz, Alcaldes, Tenientes, Comandantes y religiosos experimentaron una transformación sustancial de sus prácticas y dinámicas de relación a partir de la coyuntura de crisis, la cual se condensó en su participación o resistencia al Levantamiento. Esta situación habilitó la reconfiguración de redes de relaciones que posibilitó la concreción de la sublevación. La crisis, con su punto álgido en la sublevación, reestructuró las configuraciones de relaciones entre los actores locales y entre ellos y las esferas de poder provincial. Una vez resuelta la crisis en favor del rosismo, se generaron nuevos mecanismos de control y mediación que alteraron las prácticas de la campaña, los que aún no han sido estudiados en profundidad. En este sentido, la introducción de dispositivos de control jurídico y territorial 
sirvió para cambiar los equilibrios de poder locales y regionales. Recuperamos la noción de equipamiento político del territorio (Barriera, 2006) para comprender cómo la acción de diversos agentes imprimió un ordenamiento particular que se materializó en las instituciones, así como en las relaciones sociales, económicas y jurídicas que en él se establecían. Asimismo, estas innovaciones gubernamentales muestran y sirven para revisar los procesos de mayor alcance regional vinculados a los intentos de construcción de un Estado en clave moderna y republicana (Hespanha, 1989; Moutoukias, 2017).

\section{La coyuntura de crisis de los años 1838-1841}

La llegada al poder de Juan Manuel de Rosas en 1829 estuvo marcada por alzamientos rurales que se dieron el momento más álgido del conflicto entre unitarios y federales. El asesinato del gobernador federal Manuel Dorrego y el nombramiento de Juan Lavalle se sumaron a una serie de tensiones y conflictividades vinculadas a las prácticas sociales y económicas del ámbito rural. ${ }^{4}$ Ante este levantamiento, Rosas emergió como una garantía del orden que lograba aglutinar los intereses de diferentes sectores sociales. Había sido Comandante de milicias rurales y contaba con el apoyo de sectores populares, además pertenecía al universo de la campaña por estar entre los propietarios de tierras más importantes de la Provincia (Gelman, 2010). En 1832 dio un paso al costado en la Gobernación y comandó el avance de la frontera al sur (Reguera, 2016). Su retorno al gobierno para el segundo y extendido mandato se dio en 1835. Nuevamente en un contexto de enfrentamientos entre diferentes sectores, esta vez del propio federalismo. Una vez finalizado el conflicto, que tuvo como corolario la marginación de los federales no rosistas de la política porteña, comenzó un período de aparente tranquilidad y prosperidad en la Provincia (Halperin Donghi, 2010: 314-313). Sin embargo, en 1837 comenzó la Guerra de la Confederación Argentina contra la Confederación Peruano-Boliviana, en la que si bien Buenos Aires solo participó mediante el envío de armamento (Kloster, 2019), habilitó la aparición de tensiones y disidencias en el escenario regional. ${ }^{5}$

\footnotetext{
${ }^{4}$ Recuperamos aquí la bibliografía que ha trabajado este contexto de conflictividad rural. Una de las conclusiones principales a las que estos autores han llegado es que los alzamientos, montoneras y levantamientos sucedieron de manera más o menos autónoma y no dirigidos por el propio Rosas (Di Meglio, 2013; Fradkin, 2008; González Bernaldo de Quirós, 1987).

${ }^{5}$ La Ley Fundamental de 1825 y luego el Pacto Federal de 1831 habían establecido que Buenos Aires tenía las atribuciones de relaciones exteriores, paz y guerra. Por este motivo, el comienzo de la guerra contra la Confederación Peruano-boliviana fue impulsada por Rosas, quien designó al tucumano Alejandro Heredia como encargado de la conducción. La guerra impactó fuertemente en las provincias del norte, que debieron soportarla financiera y humanamente. Heredia fue asesinado en 1838, mientras que la guerra finalizó en 1839.
} 
El año 1838 fue la fecha bisagra que inició una crisis muy profunda, de la cual Rosas salió victorioso, pero también significó la introducción de muchos cambios en los mecanismos de sostenimiento de su poder (Gelman, 2009). En este año comenzó el bloqueo del puerto de Buenos Aires por parte de tropas francesas. ${ }^{6}$ A partir de este año, y con el preludio de la guerra en el norte, se comenzaron a configurar problemas tanto de índole económica como política que son caracterizados como una coyuntura de crisis que duró hasta el año 1841. ${ }^{7}$ Este escenario de desafíos habilitó los cuestionamientos al poder de Rosas desde diferentes sectores y motorizó los intentos para desplazarlo. Nos centraremos ahora en aquellos problemas que tuvieron un impacto importante en la campaña de Buenos Aires y que explican el clima en el que se desencadenó el Levantamiento de los Libres.

En los años de crisis, hubo dos conjuntos de medidas fiscales que apuntaban a equilibrar la balanza del gasto público que tuvieron un impacto en el ámbito rural bonaerense. Por un lado, se modificó el sistema de enfiteusis ${ }^{8}$ mediante la puesta a la venta de más de 4 millones de hectáreas que estaban bajo ese régimen. A su vez, en 1836 se duplicó el canon fijado y se decretó que se venderían las tierras de los titulares que registraran deudas en el pago. Entre 1836 y 1843 fueron escrituradas 3.411 .042 hectáreas de tierras públicas, lo que representaba el $50 \%$ de las tierras en enfiteusis. El mayor número de operaciones se produjo a partir de 1838. Desde ese año y hasta 1843 se vendieron algo más de 2.363 .500 hectáreas, beneficiándose en su mayoría los propios enfiteutas (93\%) aunque también compraron tierras los arrendatarios (D’Agostino, 2012:106). ${ }^{9}$ Por otro lado, a comienzos de 1839 también se varió la Contribución Directa ${ }^{10}$ al sumar las tierras en enfiteusis al cálculo del impuesto

\footnotetext{
${ }^{6}$ El bloqueo se explica en un contexto global de las disputas de poder entre Francia e Inglaterra. Fue justificado en el momento como una protección a ciudadanos franceses que vivían en Buenos Aires que se habían visto vulnerados.

7 El bloqueo terminó en 1840 pero recién en 1841 se resolvieron a favor del rosismo los diferentes intentos de las provincias del Interior que se habían aglutinado en la Coalición del Norte y que demandaban la reunión de un Congreso Constituyente (Paz, 2010: 46-47).

${ }^{8}$ La enfiteusis, dispuesta en 1822, implicaba la prohibición de la venta de tierras por parte del Estado y sólo se permitía la cesión a través de arrendamientos de largo plazo con el pago de un canon. Durante muchos años el canon se mantuvo estable y muchos enfiteutas no pagaban a término.

${ }^{9}$ En el partido de Monsalvo se registraron operaciones de escritura de enfiteusis de 405.348 hectáreas que correspondían al 51,7\% del total de las tierras bajo este régimen, siendo una de las secciones en las que más movimientos de este tipo hubo. En Dolores, 213.818 hectáreas en enfiteusis pasaron al dominio de particulares, lo que equivalía a, aproximadamente, el $81,5 \%$ de las tierras en este régimen (Mascioli, 2004: 158).

${ }^{10}$ El impuesto a la Contribución Directa fue creado en los años veinte y gravaba las riquezas según diferentes rubros (ganado, giro comercial, labranza y otros). El arancel aplicaba un porcentaje según el capital invertido en cada rubro. Con el pasar de los años los porcentajes se
} 
y se puso en manos de las autoridades locales la tarea de calcular los bienes a gravar. Esto hizo que aumentaran significativamente la cantidad de capitalistas censados y la recaudación. ${ }^{11}$ En parte porque los responsables de contabilizar percibían el 1\% de lo recaudado (Gelman \& Santilli, 2004: 241).

Los problemas de índole económica, que parecen haber tenido una influencia importante en el sudeste de la campaña, se articulan también con los conflictos políticos. Como veremos más adelante, muchos de los líderes del Levantamiento se encontraban entre los propietarios y enfiteutas más ricos de la región. Resulta iluminador ahondar en el escenario de oposiciones al rosismo que se configuró durante la crisis y cómo se articuló con estos personajes que habitaban el sudeste. Sin dudas, uno de los actores destacados del bando antirrosista fue Juan Lavalle. Había sido gobernador de Buenos Aires por un breve período y era reconocido por muchos como el líder que podía oponerse a Rosas. Hacia el año 1838, se encontraba en la República Oriental en el frente de Fructuoso Rivera. A partir de este año, el grupo de emigrados en Montevideo Comisión Argentina comenzó a realizar acciones que iban más allá del plano discursivo. En conjunto con federales antirrosistas y unitarios que estaban en la ciudad de Buenos Aires comenzaron a orquestar un complot para derrocar a Rosas (Zubizarreta, 2015: 31). El plan incluía acciones citadinas y en la campaña que propiciaran el acceso de Lavalle a la Provincia. El intento flaqueó cuando fue descubierta la Conspiración de Maza en junio de 1839. ${ }^{12}$ Sin embargo, Lavalle ya había estado en contacto con Pedro Castelli ${ }^{13}$ y con Marcelino Martínez Castro para coordinar la sublevación en el sur de la campaña, quienes, a pesar de lo sucedido con los Maza, decidieron avanzar en sus planes para facilitar el acceso a Lavalle.

mantuvieron fijos y además la declaración de los bienes debía hacerla cada capitalista, con lo cual la recaudación era baja.

${ }^{11}$ Los cambios en la Contribución Directa también tuvieron un impacto muy importante en los partidos del sur. Mientras que en 1837 los partidos de Dolores, Monsalvo y Tandil tenían 77, 88 y 22 capitalistas censados respectivamente, en 1839 se registraron 262 en Monsalvo, 205 en Dolores y 193 en Tandil. El aumento pudo tener varios factores, entre ellos la nueva forma de controlar y de medir el impuesto, pero lo que resulta muy significativo es que este crecimiento en la cantidad de capitalistas, que casi se triplica en los partidos de sur, no es tan evidente en otras secciones del norte o del oeste (Gelman, 2009: 80-81).

${ }_{12}$ Manuel Maza era el presidente de la Legislatura porteña y su hijo Ramón era teniente en el Regimiento de Dolores. Por intermedio de José Lavalle, hermano de Juan, Ramón había aceptado participar de la conspiración. Las redes de apoyo a Rosas y la imprudencia de los complotados le permitieron descubrir los planes y tomar medidas. Ramón y Manuel Maza fueron asesinados, el primero fusilado por orden del Gobernador y el segundo por miembros de La Mazorca, el brazo armado de la Sociedad Popular Restauradora (Di Meglio, 2012).

${ }^{13}$ Castelli y Lavalle habían sido compañeros de armas en el escuadrón de Húsares (Lacasa, 1858: 63). 
Excede a los objetivos de este trabajo explicar en detalle el clima que se vivía en la campaña. Pero podemos plantear algunas cuestiones que sirven para repensar el perfil de los actores. Jorge Gelman ha mostrado con claridad cómo en la coyuntura de crisis el rosismo comenzó a distanciarse de la "gente decente" y a convertirla en un foco de críticas y desconfianza (Gelman, 2009: 82). Aun así, siendo Rosas mismo uno de los propietarios más acaudalados de la Provincia, continuaba teniendo buenas relaciones con otros grandes terratenientes, como la familia Anchorena. ${ }^{14}$ Por este motivo, es importante matizar la capacidad de coerción que los líderes del Levantamiento puedan haber tenido para lograr movilizar miles de pobladores. ${ }^{15}$ La estrategia de Rosas fue justamente adjudicar la culpa a unos pocos para minimizar el alcance de la sublevación y perdonar a todos los que pudieran haber sido manipulados o engañados. ${ }^{16}$ Nos centraremos ahora en presentar los perfiles y trayectorias parciales de los líderes de la sublevación con el fin de detectar puntos en común que nos permitan visualizar las conexiones.

\section{Los líderes de la sublevación y sus vínculos}

\section{Perfiles diversos: un reflejo de la campaña}

Pedro Castelli, Marcelino Martínez Castro, Matías, Ezequiel y Francisco Ramos Mejía (hijo), Benito Miguens, Francisco Bernabé Madero, José Ferrari, Apolinario Barragán ${ }^{17}$ y Leonardo Domingo de la Gándara fueron los iniciadores del Levantamiento. ${ }^{18}$ La heterogeneidad de estos sujetos, tanto en sus trayectorias políticas como en sus prácticas socio-económicas, es un reflejo

\footnotetext{
${ }^{14}$ Los Anchorena, emparentada con el Gobernador Rosas, se encontraban entre las familias más acaudaladas del período (Banzato et al., 2018: 151-153).

${ }^{15}$ Una vez derrotado el Levantamiento, Prudencio Rosas eleva al Gobernador una nota en la que dice que "tenían reunidos como mil trescientos milicianos a la fuerza". Archivo Histórico de la Provincia de Buenos Aires (AHPBA), La Gaceta Mercantil. Buenos Aires 1823-1852. Volumen VIII (1838-1839). Buenos Aires Provincia. Edición digital. 9 de noviembre de 1839. En cuanto al número de detenidos, en la misma carta Prudencio Rosas sostiene que hubo alrededor de 250 muertos y 200 detenidos, pero en otras comunicaciones posteriores Nicolás Granada dice que serían 450 muertos y otros 500 prisioneros (Gelman, 2010: 65).

16 "Decreto n 1429 bis: Declarando que el motín realizado en Dolores y Monsalvo es un crimen de alta traición; y acordando una recompensa a los funcionarios públicos que permanezcan fieles a la Patria. Buenos Aires, Noviembre 9 de 1839" en Prado y Rojas (1877: 368-369).

17 De Apolinario Barragán no hemos encontrado más información que su condición de hacendado y la participación en el levantamiento de sus familiares José, Hermógenes, Pedro y Manuel. José y Hermógenes tenían tierras que les fueron confiscadas en Vivoratá y Chascomús respectivamente. Encontramos registro de sus propiedades en Para la historia. Efemérides sangrientas de la dictadura de Juan Manuel de Rosas, con un apéndice de sus robos llamados confiscaciones. Colección de artículos publicados por el «Comercio del Plata». (1849). Montevideo: Imprenta del «Comercio del Plata».

${ }_{18}$ Así los enuncia Ángel Carranza en Carranza (1919: 25).
} 
de la diversidad que imperaba en la campaña hacia fines de los años treinta del siglo XIX. Y es también una muestra de las divergencias al interior del federalismo y de las formas locales del poder rosista.

Pedro Castelli y Marcelino Martínez Castro son las figuras principales en la articulación entre los conspiradores en la ciudad de Buenos Aires y en Montevideo con los Libres del Sur en la campaña. Pedro era hijo de Juan José Castelli, figura clave de la Revolución de Mayo, y de María Rosa Lynch. Nació en 1796 en Buenos Aires y tuvo una trayectoria destacada en las Guerras de Independencia. Participó en la Batalla de San Lorenzo (1813), en el Sitio de Montevideo (1814) y en las fuerzas de represión contra las montoneras litorales (1818-1820). En noviembre de 1818 fue designado capitán del Regimiento de Húsares de la Unión. En 1823, con el rango de Sargento Mayor de Caballería, se retiró de la actividad militar para dedicarse a tareas rurales. Fue administrador de la Estancia La Esperanza de la compañía Zimmerman hasta que, con la ayuda de su amigo Manuel Campos, pudo comprar su propia finca en el Cerro Paulino en las Sierras del Volcán. ${ }^{19}$ Castelli fue convocado a la sublevación por Martínez Castro (1810-s/f), quien estaba desde 1828 a cargo de una estancia de su hermano mayor Ladislao en la Sierra de los Padres (Mazzanti et al., 1991: 38). Durante la gobernación de Lavalle se ofreció para colaborar, lo que le costó su detención cuando llegó Rosas al poder. Por este pasado vinculado al unitarismo, fue convocado por los organizadores de la Conspiración de Maza. ${ }^{20}$

A continuación, profundizamos en los otros líderes involucrados en la rebelión. Ordenamos la presentación en apartados que están basados en criterios analíticos, que nos permitan reconstruir las trayectorias individuales y familiares de los actores destacados. Sin embargo, como veremos, en la práctica de los actores los criterios se superponen y entrelazan.

\section{Los hombres de más fortuna y saber}

Las familias Ramos Mejía y Miguens, junto con Campos, Sáenz Valiente, Álzaga, Ezeiza y Díaz Vélez evocan el pasado de las élites rioplatenses más destacadas. De todas ellas hubo algún miembro, o varios, que tomaron parte en el Levantamiento. Este hecho era percibido por los actores implicados, ${ }^{21}$ ya que Castelli en su proclama señala:

\footnotetext{
${ }^{19}$ La reconstrucción biográfica de Pedro Castelli la hemos realizado a partir de: Carranza (1919: 28-29); Rosa (1962: 414); Muzzio (1920: 126) y Diccionario Biográfico electrónico [Real Academia de la Historia]. (2018). http://dbe.rah.es/db e

${ }^{20}$ Ésta información biográfica y relacional de Marcelino Martinez Castro es presentada por Carranza (1919: 26-28).

${ }^{21}$ En su análisis de las motivaciones de la sublevación, Jorge Gelman sostiene que, ante los frentes hostiles, el gobierno de Rosas había generado una dinámica caracterizada por el faccionalismo extremo y la movilización de los sectores populares. En este contexto, la llamada
} 
“...valientes paisanos ¡libertad o morir con honor! Que el tirano a quien vosotros elevasteis a la cumbre del poder ¡muera! y que su sangre lave las ofensas que se os ha hecho. ¿No os conmueve, ver entrelazados en nuestras filas a los hombres de más fortuna y saber? ¿No dejan como vosotros sus familias y sus comodidades y marchan a la guerra a participar de sus males? Imitad este ejemplo y ocuparéis en la historia un lugar eminente, $y$ en el afecto de nuestros compatriotas su reconocimiento sin límites..." (Carranza, 1919: 187-188).

Como ya citamos previamente, los tres hermanos Ramos Mejía, Francisco (1813-s/f), Matías (1810-1885) y Ezequiel (1818-1896) integraron el núcleo rebelde. Junto con ellos se sumó Francisco Bernabé Madero (1816-1896), quien llegaría a ser vicepresidente entre 1880 y 1886 durante la presidencia de Roca. Madero se casó en 1848 con Marta Ramos Mejía, mientras que su hermana Francisca estaba unida con Matías Ramos Mejía. Francisco Hermógenes Ramos Mejía, padre de los anteriores, pertenecía a una familia de la burocracia virreinal. Luego tomó parte en la Revolución. Más adelante se dedicó a la vida rural, lo que le permitió trazar vínculos con los indígenas de las pampas, de quienes adquirió 125.000 hectáreas (Banzato et al., 2018: 145-146).

La familia Miguens arribó a la campaña de Buenos Aires a través de la adquisición de tierras realizada por Marcos Miguens, un español de Galicia que llegó a mediados del siglo XVIII al Río de la Plata y se dedicó a actividades comerciales. También ocupó el cargo de Alcalde de Hermandad en Magdalena, donde era propietario. Sus hijos Juan Gualberto y Francisco profundizaron en las actividades comerciales de su padre y continuaron adquiriendo tierras en la Provincia de Buenos Aires, conforme se consolidó la expansión de la frontera. Juan, a su vez, participó activamente en la defensa de las Invasiones Inglesas y en las Guerras de Independencia. En los años veinte formó parte de la Sala de Representantes (Banzato et al., 2018: 146). Sus hijos José Eulalio, Juan Luciano y Estanislao participaron del Levantamiento, lo que les costó el embargo de sus propiedades. Entre los hijos de Francisco se destacan Benito (nombrado más arriba como uno de los miembros principales de la sublevación), Felipe Santiago y Martiniano. Los tres eran propietarios y enfiteutas del sudeste de la Provincia e integraron las listas de capitalistas del impuesto a la Contribución Directa en 1839, como así también sus primos José y Estanislao. Benito había sido militar y Juez de Paz de Dolores, mientras que Felipe había integrado la Sala de Representantes (Banzato et al., 2018: 150). En el legajo del Juzgado de Paz de Monsalvo, encontramos una breve referencia a Benito Miguens. Dentro de parte cuatrimestral, con fecha 31 de agosto de 1839, el Juez de Paz José

"gente decente" se había convertido progresivamente de sospechosa de complicidad con los enemigos unitarios (Gelman, 2009: 82). 
Manuel Otamendi enlista a los tenientes y alcaldes de los cuarteles en los que se subdivide el partido. Cuando reseña al Teniente Alcalde Don José Fuentes, del cuartel $n^{\circ} 2$, señala que: "ha prestado servicios personales bajo las órdenes del comandante Don Benito Miguens en la 1ra Restauración y en la 2da con sus intereses, es buen servidor en cumplimiento de su deber". ${ }^{22}$

Manuel Isidro Campos (1796-1854), señalado en el apartado anterior como amigo de Pedro Castelli, y Martín Teodoro Campos (1798-1878) eran descendientes de una familia que tenía anclaje desde tiempos virreinales. Su padre Gaspar José Campos participó en la defensa de las Invasiones Inglesas y tuvo un rol importante en el poblamiento al sur del Río Salado (Domínguez Soler, 2006: 91). ${ }^{23}$ Manuel y Martín desempeñaron tareas militares durante las Guerras de Independencia. Luego se dedicaron a la actividad rural, siendo enfiteutas y propietarios en la Provincia de Buenos Aires. ${ }^{24}$ Según J. Gelman (2009), durante el rosismo eran sospechados de unitarios. Además, eran tíos, por parte de su hermana Hilaria, de Pedro Lacasa (Domínguez Arribas, 2003: 221). Lacasa (1810-1869) fue escritor y biógrafo de Lavalle y cumplió un rol importante en la gesta del Levantamiento. Invitó a participar a sus hermanos Pastor y Mariano, tenientes que cumplían funciones en el campamento de Tapalqué.

Bernabé (1800-s/f), ${ }^{25}$ Anselmo (1804-1867) y Francisco (1793-1868) Saénz Valiente eran hermanos. Su madre era Juana María Pueyrredón, hermana de Juan Martín, Director Supremo de las Provincias Unidas entre 1816 y 1819. Su padre era Anselmo Saénz Valiente, un español arribado a Buenos Aires hacia mediados del siglo XVIII que se dedicó al comercio y tuvo funciones en la burocracia virreinal. Tenía un vínculo muy estrecho con Martín de Álzaga, otro español miembro destacado del Consulado de Comercio de Buenos Aires

\footnotetext{
${ }^{22}$ El Juez de Paz de Monsalvo, Don José M. Otamendi a Juan Manuel de Rosas, Monsalvo, 31 de agosto de 1839. Relación de los alcaldes y tenientes de este partido con expresión de los nombres, nota de su opinión, lugar de su residencia, fortuna, edad y Patria. Archivo General de la Nación (AGN), Sala X, legajo núm. 21-4-13. Según muestra Jorge Gelman, Benito era considerado "buen federal", mientras que Felipe y Eusebio estaban sospechados de unitarios (Gelman, 2009: 108-109).

${ }^{23}$ De acuerdo con Carranza (1919), Gaspar Campos junto con otros hacendados de la zona, tuvo un rol destacado en el crecimiento del pueblo de Dolores, refundado por el Capitán Ramón Lara en 1827.

${ }^{24}$ Encontramos registro de sus propiedades, que fueron confiscadas luego del Levantamiento en: Para la historia. Efemérides sangrientas de la dictadura de Juan Manuel de Rosas, con un apéndice de sus robos llamados confiscaciones. Colección de artículos publicados por el «Comercio del Plata». (1849). Montevideo: Imprenta del «Comercio del Plata».

25 De acuerdo con Carranza (1919: 111), Lavalle, convencido por Marcelino Martinez de las posibilidades de iniciar una rebelión en la campaña sur, escribió cartas a "Bernabé Saenz Valiente y demás amigos".
} 
(Moutoukias, 2017: 14). Los hermanos Sáenz Valiente que participaron del Levantamiento eran hacendados en la zona sur.

Martín Gregorio (1814-1870) y Félix Gabino (1815-1877) eran hijos de Félix de Álzaga y nietos de Martín de Álzaga, quien tuvo un rol destacado en la defensa de las Invasiones Inglesas y que finalmente fue fusilado acusado de conspirar contra la Revolución. Félix padre hizo carrera militar durante las Guerras de Independencia y luego detentó posiciones públicas en la Provincia. Fue muy cercano a Rosas durante su primera gobernación y luego tomó posiciones afines a las de los federales antirrosistas. A pesar de que aún estaba vivo, no formó parte en el Levantamiento de los Libres, aunque sí lo hicieron sus dos hijos, quienes poseían gran cantidad de tierras en el sudeste de la Provincia (D'Agostino, 2007; Muzzio, 1920: 33).

Juan Ramón (1787-1864) y Valentín Ezeiza (1805-1871) eran hacendados del sudeste de la Provincia. Nacieron en Gualeguay y heredaron tierras en la zona de la Mar Chiquita. Su padre, Pedro Pablo Ezeiza era propietario en Entre Ríos y había obtenido los campos en Buenos Aires mediante donación del Cabildo de Buenos Aires por sus servicios prestados. Juan Ramón y Valentín se encontraban entre los mayores propietarios de tierras para 1839 (Banzato et al., 2018: 144-145). Carranza sostiene que fueron iniciados por Castelli para sumarse al Levantamiento y en su estancia "El Durazno" tuvieron lugar algunas de las reuniones organizativas (Carranza, 1919: 121-122). También se vio implicado en el Levantamiento el mayordomo de la estancia de Valentín, Sebastián Fondevila (Carranza, 1919: 123), que había desempeñado durante siete años la función de Teniente Alcalde del cuartel $\mathrm{n}^{\circ} 5$ del partido de Monsalvo. ${ }^{26}$

Eustaquio Antonio Díaz Vélez nació en Buenos Aires en 1782. Hijo de Francisco José Díaz Vélez, un comerciante español muy acaudalado y miembro del Cabildo, y de María Petrona Aráoz Sánchez de Lamadrid, oriunda del Tucumán e hija de una importante familia colonial. Se dedicó al comercio familiar y luego realizó una carrera militar muy destacada durante la Revolución y las Guerras de Independencia. Poseía tierras en la zona del Río Salado y durante las décadas del veinte y del treinta adquirió aún más en forma de enfiteusis. También se desempeñó como Juez de Paz. Se convirtió en el mayor propietario individual de campos en la provincia de Buenos Aires. Con las ventas de la década de 1830 adquirió 50.220 hectáreas y fue el $6^{\circ}$ contribuyente de la campaña en 1839 (Banzato et al., 2018: 154). No participó de la batalla de Chascomús, pero sí lideró las fuerzas rebeldes en la zona de Tandil durante el Levantamiento.

\footnotetext{
${ }^{26}$ El Juez de Paz de Monsalvo, Don José M. Otamendi a Juan Manuel de Rosas, Monsalvo, 31 de agosto de 1839. Relación de los alcaldes y tenientes de este partido con expresión de los nombres, nota de su opinión, lugar de su residencia, fortuna, edad y Patria. AGN, Sala X, legajo núm. 21-4-3.
} 


\section{La dirección de las armas}

La sublevación de Los Libres fue, además de un acto ideológico y político, una acción militar. Por ello, una de las preocupaciones principales de los gestores era conseguir la adhesión de militares activos. Ya vimos que Pedro Lacasa sumó a sus hermanos que estaban destinados en el Regimiento de Tapalqué. También sabemos que muchos de los que participaron tenían trayectoria militar que se remontaba a los tiempos de las Guerras de Independencia. Veamos ahora quiénes fueron los hombres de armas que adhirieron al movimiento sedicioso con el fin de conducir las acciones de enfrentamiento militar.

En primer lugar, se encuentra Manuel Leoncio Rico (1798-1841). Pertenecía a una familia de recursos modestos, por lo que se dedicó al trabajo rural en la zona norte de Buenos Aires. Se interesó por la carrera castrense y formó parte de la expedición al sur de los años 1833 y 1834. A partir de allí combinó las dos actividades, rural y militar. Era el segundo a cargo del Regimiento de Campaña $n^{\circ} 5$, con sede en Dolores, en donde era vecino y ejercía tareas campestres. Carranza evoca una situación de descontento entre Rico y Rosas, y luego entre Rico y Narciso del Valle, que fue aprovechada por los Libres para ganar su adhesión (Carranza, 1919: 120-121; Muzzio, 1920: 354355). Rico se convirtió en el líder militar de la sublevación y se encargó de sumar a sus subordinados. De su puño son la mayoría de las cartas producidas por los sublevados al momento del Levantamiento. ${ }^{27}$ Zacarías Márquez era Capitán y se desempeñaba como teniente de milicias de Dolores. Era natural de Santa Fe, pero llevaba años avecindado en Dolores. Se plegó a la sublevación junto con Rico, que era su superior y el Capitán Crispín Peralta. Márquez es el principal interlocutor de las misivas de Rico durante el Levantamiento (Carranza, 1919: 118, 128, 177; Muzzio, 1920: 261).

Otros militares que tuvieron una participación destacada liderando las fuerzas rebeldes fueron Francisco Olmos (1800-1867) y José Mendiola. Mendiola estaba designado en Chascomús como Comandante de milicias y fue quien encabezó el pronunciamiento de dicho pueblo junto con Villarino y Posse. Fue el Comandante de la vanguardia durante la batalla de Chascomús. Olmos, al igual que Rico, provenía de una familia modesta y se dedicó a la actividad rural como peón. Desde muy joven integró el cuerpo de blandengues y formó parte de las avanzadas del gobierno de Martín Rodríguez en la frontera sur bajo las órdenes del Capitán Benito Miguens. En 1835 fue investido Comandante de milicias de Chascomús y para 1839 ya era sargento mayor de línea graduado de teniente coronel y comandante del $5^{\circ}$ escuadrón del regimiento $\mathrm{N}^{\circ} 6$ de milicias

27 Contemporáneamente al Levantamiento fueron publicadas en el diario oficial La Gaceta Mercantil. Luego, las encontramos recopiladas en Echeverría (1854: 43-202). 
de caballería de campaña encargado del cantón de la boca del Salado. Poseía un pequeño establecimiento en el paraje denominado la Limpia(Carranza, 1919: 182-183).

\section{Jueces, alcaldes y tenientes: las redes locales al servicio de los Libres}

La capacidad de movilización de los sublevados radicó en la notoriedad que muchos de ellos tenían en las zonas en que se avecindaban. Notoriedad que en muchos casos estaba dada por su participación en los Juzgados de Paz, es decir, en la propia red institucional de gobierno. Entre estos personajes podemos mencionar a José Otamendi, que era Juez de Paz de Monsalvo al momento del Levantamiento y había sido Teniente Alcalde del Cuartel $\mathrm{n}^{\circ} 5$ del mismo partido, en donde tenía una estancia. También participó de la sublevación su hermano Fernando, que era hacendado en la zona. ${ }^{28}$

Leonardo Domingo de la Gándara nació en Buenos Aires en 1785. Se unió a las fuerzas revolucionarias y fue teniente de milicias. Ocupó varios cargos en la función pública: fue Juez de Paz de Morón en 1822 y de Chascomús en 1828. También detentó el puesto de diputado en la Legislatura porteña y de vicepresidente de la Administración del Crédito Público. En 1829 fue presidente de la Comisión de Abastos y provisiones y en 1831 capitán de milicias, inspector del puerto y formó parte de la Comisión de Hacendados. Tenía una estancia en la Laguna Vitel, en la costa de Samborombóm, ${ }^{29}$ que era lindante con los campos de José Ferrari (Muzzio, 1920: 188). Ferrari fue un hacendado nacido en Buenos Aires que dedicó a las tareas rurales, alcanzando en pocos años de labor una posición acomodada, que le permitió adquirir tierras sobre las costas del rio Samborombón, allí fundó un importante establecimiento ganadero. Según Gelman, estaba sospechado de filiación unitaria (Gelman, 2009: 108). Ferrari es mencionado por Carranza como uno de los gestores del Levantamiento, mas no hemos encontrado información biográfica más precisa.

Además, hubo otros miembros del Juzgado de Paz de Monsalvo que tuvieron participación en la rebelión. Entre ellos se encuentra Leonardo Piedrabuena, que fue Juez de Paz en 1837 y era propietario de la estancia Espuela Verde, en la que tuvieron lugar reuniones conspirativas. ${ }^{30} \mathrm{~A}$ su vez,

\footnotetext{
${ }^{28}$ El Juez de Paz de Monsalvo, Leonardo Piedrabuena a Juan Manuel de Rosas, Monsalvo, 31 de agosto de 1837. Relación de los Alcaldes y Tenientes de esta sección con expresión de nombres, nota de la opinión, lugar de residencia, fortuna, edad y patria, AGN, Sala X, legajo núm. 21-4-3; Carranza (1919: 73). Muzzio (1920: 301); Diccionario Biográfico electrónico [Real Academia de la Historia]. (2018). http://dbe.rah.es/db e

${ }^{29}$ La biografía de Domingo de la Gándara la reconstruimos a partir de Carranza (1919: 179-181). y de Muzzio (1920: 197-198).

30 "El Juez de Paz de Monsalvo, Leonardo Piedrabuena a Juan Manuel de Rosas, Monsalvo, 31 de agosto de 1837. Relación de los Alcaldes y Tenientes de esta sección con expresión de
} 
Nemesio Barbosa que era Teniente Alcalde del Cuartel $n^{\circ} 5$, Santiago Bello e Isidoro Fulcos quienes ejercían como Tenientes Alcaldes del Cuartel $n^{\circ} 1 .{ }^{31}$ Fulcos era propietario en el Rincón de Ajó y fue embargado luego del Levantamiento. ${ }^{32}$ En el Juzgado de Paz de Dolores se destacan Saturnino Correa, que fue Juez de Paz sustituto a comienzos de $1839^{33}$ y Tiburcio Lens, que había sido Alcalde y fue nombrado por los sublevados como Juez de Paz una vez comenzada la rebelión (Carranza, 1919: 125-130).

Por otra parte, en el partido de Chascomús encontramos también personas que desempeñaron un rol importante en la articulación del Levantamiento. En primer lugar, Francisco Villarino (1787-1875), propietario en varias zonas de la Provincia de Buenos Aires. Villarino tuvo una participación activa en los eventos del año '28 a favor de los federales dorreguistas. En 1832 fue nombrado Juez de Paz de Chascomús y participó de la Expedición al Desierto comandada por Rosas entre 1833 y 1834. Su filiación hacia el federalismo más moderado no le impidió acceder al puesto de Comandante de Infantería del Regimiento n 6 (Carranza, 1919: 172-173). ${ }^{34}$ Cuando sucedió el pronunciamiento de Dolores se encontraba en Chascomús y fue avisado por Crámer del Levantamiento. Villarino se encargó de hacer llegar la información a su sobrino Wenceslao Posse (1818-s/f), un joven comerciante del poblado que tenía vínculos con José Mendiola. Por último, debemos nombrar a Antonio Pillado (1809-1879), gallego de nacimiento, que ofició como secretario de Pedro Castelli durante el Levantamiento, con quien lo unía la amistad. Era comerciante y habitante del sur de la Provincia. Fue el encargado de elaborar el acta del pronunciamiento de Dolores (Carranza, 1919: 128; Muzzio, 1920: 322).

\section{Ambrosio Crámer: trayectorias y vínculos en la campaña}

Ambrosio Crámer nació en Francia en 1792, participó de las Guerras Napoleónicas y luego emigró al Río de la Plata, en donde se sumó a las Guerras de Independencia. En 1822 contrajo nupcias con María Francisca Capdevila, cuyo tío, Pedro de Alcántara Capdevila, era propietario de tierras en el sudeste.

nombres, nota de la opinión, lugar de residencia, fortuna, edad y patria", AGN, Sala X, legajo núm. 21-4-3; Carranza (1919: 122).

31 “El Juez de Paz de Monsalvo, Leonardo Piedrabuena a Juan Manuel de Rosas, Monsalvo, 31 de agosto de 1837. Relación de los Alcaldes y Tenientes de esta sección con expresión de nombres, nota de la opinión, lugar de residencia, fortuna, edad y patria", AGN, Sala X, legajo núm. 21-4-3.

32 Para la historia. Efemérides sangrientas de la dictadura de Juan Manuel de Rosas, con un apéndice de sus robos llamados confiscaciones. Colección de artículos publicados por el «Comercio del Plata» (1849). Montevideo: Imprenta del «Comercio del Plata»

${ }^{33}$ En varias misivas del Juzgado de Paz de Dolores de marzo y abril de 1839 encontramos la firma de Saturnino Correa como "Juez de Paz sustituto", en AGN, Sala X, legajo núm. 21.1.2.

${ }^{34}$ Diccionario Biográfico electrónico [Real Academia de la Historia]. (2018). http://dbe.rah.es/db e 
Al fallecer Pedro Capdevila en 1828 transfirió sus tierras en enfiteusis a Ladislao Martínez Castro (hermano de Marcelino) (Mazzanti et al., 1991: 37). Crámer era miembro accionista de la Sociedad Rural (Flores, 2010: 102). En el mismo año dirigió el reconocimiento del fuerte del Carmen del Río Negro ${ }^{35}$ y en 1825 formó parte de la comisión que comandó Juan Manuel de Rosas al sud de la Provincia. De acuerdo con el diario de esta expedición De Angelis (1837: 154213), recorrieron mayormente el sudeste. Crámer asistió con el fin de representar los derechos de la Sociedad del Volcán ${ }^{36}$ y figura como militar reformado y agregado a la Comisión. De acuerdo con el diario, Crámer asistió "con su dependiente, un capataz, ocho peones, una carretilla toldada, 10 novillos y 60 caballos" (De Angelis, 1837: 172).

Era propietario de la estancia La Postrera, situada en la margen sur del Río Salado y correspondiente al Cuartel IV del partido de Dolores, en donde funcionaba una pulpería. También tenía otro establecimiento en la zona llamado Los Rengos (Mascioli, 2002: 119). En el censo realizado en 1836 figura como dueño de tres esclavos en Dolores (Pirali, 2013: 57). Fue agrimensor del Departamento Topográfico de Buenos Aires y como tal realizó más de ciento diez mensuras a terrenos de particulares entre 1826 y 1839, la mayoría de ellas, alrededor de cien, al sur del Río Salado. Algunas de las personas que solicitaron sus servicios fueron: Pedro Capdevila, Félix Álzaga, Pedro y Bernabé Sáenz Valiente, Leonardo Domingo de la Gándara, José de la Quintana, Eusebio, Felipe y José Miguens, Juan Ramón Ezeiza, la compañía Zimmerman \& Cía (para la que supo trabajar Pedro Castelli) y Eustaquio Díaz Vélez. Todas ellas, salvo dos mensuras realizadas para Pedro Capdevila en Avellaneda y en Berazategui fueron realizadas en el sud de la provincia, en los partidos de Dolores, Monsalvo, Chascomús y en la zona del Fuerte Independencia. ${ }^{37}$

${ }^{35}$ El diario completo de la exploración, escrito por Crámer, se encuentra compilado en De Angelis (1837: 910-918).

${ }^{36}$ Inferimos que la Sociedad del Volcán refiere o a la Compañía de Tierras del Volcán o a la Sociedad Rural Argentina, de la que Crámer era parte, que se habían conformado con el fin de activar la productividad ganadera mediante enfiteusis (Mazzanti et al., 1991: 34-36). En relación a esto, Valeria D'Agostino comenta que Crámer recibió una extensión en enfiteusis como pago por sus servicios prestados a la Sociedad del Volcán (D’Agostino, 2012: 92)

${ }^{37}$ Avellaneda: Capdevila Pedro (1829); Ayacucho: Álzaga Félix (1834), Piedrabuena Leonardo (1836); Balcarce: Sáenz Valiente Francisco (1833); Berazategui: Capdevila Pedro (1829); Chascomús: Capdevila Pedro (1827); Dolores: Sáenz Valiente Pedro (1827); General Guido: Quintana José (1834); General Lavalle: Sáenz Valiente Bernabé (1830, 1833); General Madariaga: Zimmerman \& Cía. (1836); General Pueyrredón: Capdevila Pedro (1826); Lobería: Sociedad Rural Tierras Sobre Costas de la Lobería (1836); Mar Chiquita: Capdevila Fernández José (1828), Ezeiza Juan R y otros (1833); Rauch: Gándara Leonardo Domingo (1827), Díaz Vélez Eustaquio (1826); Tandil: Miguens José (1827), Miguens Eusebio y Felipe (1827). Información extraída del Catálogo General de Mensuras de la Provincia de Buenos Aires existentes en el archivo de la repartición desde 1824 al 30 de junio de 1944, publicado en 1945 por el Ministerio de Obras Públicas de la Provincia de Buenos Aires. 
Además de realizar mensuras, Crámer diseño el trazado del pueblo de Tandil (D’Agostino, 2012: 93).

La figura de Crámer nos devela una cuestión central para la sublevación: el conocimiento del espacio en el que se desarrollan los hechos y la puesta en valor de dichos saberes. Pero, además, a través de los registros de las mensuras, sabemos que su oficio de agrimensor le permitió interactuar con muchos de quienes serían luego sublevados. Podemos suponer que estas experiencias de encuentro en los terrenos a medir habrían sido una buena oportunidad para intercambiar ideas y opiniones de los devenires de la Provincia entre hombres que no eran ajenos a la política y que habían tenido participación en el proceso revolucionario e independentista. En el caso de Crámer, su relación con la Provincia a través del Departamento Topográfico y las expediciones, le permitió acceder a un conocimiento privilegiado del entorno de la campaña, que se materializó también en su acceso a la tierra. En conclusión, las prácticas de un actor clave iluminan los vínculos de lo local con lo global. Su trayectoria cruza la problematización del Levantamiento que planteamos y consideramos que puede ser una puerta de entrada para profundizar en la dinámica relacionar detrás de la sublevación.

\section{Algunos puntos en común}

A través de la bibliografía y las fuentes hemos podido recuperar biografías parciales de los participantes. Con el objetivo de sintetizar lo hasta ahora presentado, realizamos ahora una breve recapitulación de algunos sujetos, focalizando en aquellos de los que poseemos más información. Tomamos a dieciocho individuos. A partir de la siguiente tabla (Tabla 1) intentaremos esbozar algunas reflexiones e ideas que nos permitan adentrarnos aún más en la dinámica de los actores que tomaron las armas contra Rosas. 
Tabla 1

\begin{tabular}{|c|c|c|c|c|}
\hline $\begin{array}{l}\text { Nombre } \\
\text { y } \\
\text { apellido }\end{array}$ & $\begin{array}{l}\text { Edad } \\
\text { en } \\
1839\end{array}$ & $\begin{array}{l}\text { Antecedentes } \\
\text { (sociales, económicos, } \\
\text { políticos) }\end{array}$ & $\begin{array}{l}\text { Lugares } \\
\text { asociados }^{39}\end{array}$ & $\begin{array}{l}\text { Vínculos con } \\
\text { otros }\end{array}$ \\
\hline $\begin{array}{l}\text { Pedro } \\
\text { Castelli }\end{array}$ & 43 & $\begin{array}{l}\text { Militar (húsares); } \\
\text { propietario; buen } \\
\text { federal }\end{array}$ & $\begin{array}{l}\text { Cerro Paulino } \\
\text { (Monsalvo - } \\
\text { sierras del } \\
\text { Volcán) } \\
\text { Estancia La } \\
\text { Esperanza } \\
\text { (Zimmerman } \\
\text { \&Cia) en los } \\
\text { Montes Grandes } \\
\text { del Tuyú }\end{array}$ & $\begin{array}{l}\text { Juan Lavalle; } \\
\text { Manuel } \\
\text { Campos; } \\
\text { Marcelino } \\
\text { Martínez } \\
\text { Castro }\end{array}$ \\
\hline $\begin{array}{l}\text { Marcelino } \\
\text { Martinez } \\
\text { Castro }\end{array}$ & 29 & $\begin{array}{l}\text { Colaborador de } \\
\text { Lavalle en } 1828 \\
\text { A cargo de un } \\
\text { establecimiento rural } \\
\text { de su hermano } \\
\text { Ladislao }\end{array}$ & $\begin{array}{l}\text { Laguna de los } \\
\text { Padres } \\
\text { (Monsalvo) }\end{array}$ & $\begin{array}{l}\text { Lavalle } \\
\text { (Comisión } \\
\text { Argentina); } \\
\text { Pedro } \\
\text { Castelli }\end{array}$ \\
\hline $\begin{array}{l}\text { Ezequiel } \\
\text { Ramos } \\
\text { Mejía }\end{array}$ & 21 & \multirow{3}{*}{$\begin{array}{l}\text { Sospechados de } \\
\text { unitarios, propietarios } \\
\text { rurales }\end{array}$} & & \multirow{3}{*}{$\begin{array}{l}\text { Francisco } \\
\text { Bernabé } \\
\text { Madero; } \\
\text { Marcelino } \\
\text { Martínez } \\
\text { Castro }\end{array}$} \\
\hline $\begin{array}{l}\text { Francisco } \\
\text { Ramos } \\
\text { Mejía } \\
\end{array}$ & 26 & & $\begin{array}{l}\text { Estancia Los } \\
\text { Tapiales (La } \\
\text { Matanza) }\end{array}$ & \\
\hline $\begin{array}{l}\text { Matías } \\
\text { Ramos } \\
\text { Mejía }\end{array}$ & 29 & & $\begin{array}{l}\text { Estancia } \\
\text { Marihuincul } \\
\text { (Monsalvo) }\end{array}$ & \\
\hline Benito & & Capitán de Milicias; & Costa de & Francisco \\
\hline
\end{tabular}

\footnotetext{
${ }^{38}$ Los datos de si eran considerados buenos federales o sospechados de unitarios y en algunos casos su participación en los elencos de justicia de paz, los extrajimos de Gelman (2009: 107109).

${ }^{39} \mathrm{La}$ información consignada y no referida previamente la tomamos de Para la historia. Efemérides sangrientas de la dictadura de Juan Manuel de Rosas, con un apéndice de sus robos llamados confiscaciones. Colección de artículos publicados por el «Comercio del Plata» (1849). Montevideo: Imprenta del «Comercio del Plata».
} 


\begin{tabular}{|c|c|c|c|c|}
\hline Miguens & & $\begin{array}{l}\text { Juez de Paz (Dolores y } \\
\text { Monsalvo); Buen } \\
\text { Federal; propietario y } \\
\text { enfiteuta }\end{array}$ & $\begin{array}{l}\text { Sambormbón; } \\
\text { diferentes zonas } \\
\text { de la Sección } \\
\text { Independencia y } \\
\text { Monsalvo. }\end{array}$ & $\begin{array}{l}\text { Ramos } \\
\text { Mejía, }{ }^{40} \text { Juan } \\
\text { Francisco } \\
\text { Olmos }\end{array}$ \\
\hline $\begin{array}{l}\text { Leonardo } \\
\text { Domingo } \\
\text { de la } \\
\text { Gándara } \\
\end{array}$ & 54 & $\begin{array}{l}\text { Juez de Paz; cargos } \\
\text { varios en la función } \\
\text { pública; propietario y } \\
\text { enfiteuta }\end{array}$ & $\begin{array}{l}\text { Lagunas de Vitel } \\
\text { (Chascomús) }\end{array}$ & $\begin{array}{l}\text { Terrenos } \\
\text { lindantes con } \\
\text { Ferrari }\end{array}$ \\
\hline $\begin{array}{l}\text { Martín } \\
\text { Campos }\end{array}$ & 41 & \multirow{2}{*}{$\begin{array}{l}\text { Militares de las } \\
\text { Guerras de } \\
\text { Independencia; } \\
\text { propietarios; } \\
\text { sospechados de } \\
\text { unitarios }\end{array}$} & $\begin{array}{l}\text { Montes Grandes, } \\
\text { Los Nogales } \\
\text { (Monsalvo) }\end{array}$ & \multirow{2}{*}{$\begin{array}{l}\text { Pedro } \\
\text { Castelli; } \\
\text { Pedro Lacasa } \\
\text { (sobrino) }\end{array}$} \\
\hline $\begin{array}{l}\text { Manuel } \\
\text { Campos }\end{array}$ & 43 & & $\begin{array}{l}\text { Médano Alto } \\
\text { (Monsalvo) }\end{array}$ & \\
\hline $\begin{array}{l}\text { Félix } \\
\text { Álzaga }\end{array}$ & 24 & \multirow{2}{*}{$\begin{array}{l}\text { Propietarios y } \\
\text { enfiteutas; buenos } \\
\text { federales }\end{array}$} & \multirow{2}{*}{$\begin{array}{l}\text { Estancia Bella } \\
\text { Vista (Dolores); } \\
\text { Partido de Tandil }\end{array}$} & \multirow{2}{*}{$\begin{array}{l}\text { Su padre } \\
\text { había sido } \\
\text { muy cercano } \\
\text { a Rosas; Juan } \\
\text { Francisco } \\
\text { Olmos }\end{array}$} \\
\hline $\begin{array}{l}\text { Martín } \\
\text { Álzaga }\end{array}$ & 25 & & & \\
\hline $\begin{array}{l}\text { Juan } \\
\text { Ramón } \\
\text { Ezeiza }\end{array}$ & 52 & $\begin{array}{l}\text { Propietario y } \\
\text { enfiteutas; buen } \\
\text { federal; teniente de } \\
\text { Monsalvo }\end{array}$ & \multirow[t]{2}{*}{$\begin{array}{l}\text { Estancia "El } \\
\text { Durazno" en Mar } \\
\text { Chiquita } \\
\text { (Monsalvo) }\end{array}$} & \multirow[t]{2}{*}{$\begin{array}{l}\text { Mayordomo } \\
\text { y Alcalde } \\
\text { Fondevila }\end{array}$} \\
\hline $\begin{array}{l}\text { Valentín } \\
\text { Ezeiza }\end{array}$ & 34 & $\begin{array}{l}\text { Propietario y } \\
\text { enfiteutas; buen } \\
\text { federal }\end{array}$ & & \\
\hline $\begin{array}{l}\text { Eustoquio } \\
\text { Díaz } \\
\text { Vélez } \\
\end{array}$ & 57 & $\begin{array}{l}\text { Enfiteuta, propietario; } \\
\text { juez de Paz }\end{array}$ & Tandil & \\
\hline $\begin{array}{l}\text { Manuel } \\
\text { Rico }\end{array}$ & 42 & $\begin{array}{l}\text { Militar del regimiento } \\
\mathrm{n}^{\circ} 5 \text { de Campaña; } \\
\text { propietario }\end{array}$ & Dolores & $\begin{array}{l}\text { Zacarías } \\
\text { Marquez }\end{array}$ \\
\hline $\begin{array}{l}\text { Ambrosio } \\
\text { Crámer }\end{array}$ & 47 & $\begin{array}{l}\text { Militar, agrimensor } \\
\text { del DT; enfiteuta y }\end{array}$ & $\begin{array}{l}\text { Establecimientos } \\
\text { La Postrera y los }\end{array}$ & $\begin{array}{l}\text { Familia } \\
\text { Capdevila, }\end{array}$ \\
\hline
\end{tabular}

${ }^{40}$ Según Carranza (1919: 28), Francisco Ramos Mejía y Benito Miguens eran amigos y fue el primero quien invitó al segundo a la sublevación. 


\begin{tabular}{|l|l|l|l|l|}
\hline & & $\begin{array}{l}\text { propietario; } \\
\text { sospechado de } \\
\text { unitario }\end{array}$ & $\begin{array}{l}\text { Rengos (Dolores); } \\
\text { Sociedad del } \\
\text { Volcán (Tandil); } \\
\text { terrenos en la } \\
\text { Sección } \\
\text { Independencia }\end{array}$ & $\begin{array}{l}\text { Sociedad del } \\
\text { Volcán; } \\
\text { titulares de } \\
\text { mensuras }\end{array}$ \\
\hline $\begin{array}{l}\text { Juan } \\
\text { Francisco } \\
\text { Olmos }\end{array}$ & 39 & $\begin{array}{l}\text { Militar: sargento; buen } \\
\text { federal }\end{array}$ & $\begin{array}{l}\text { Chascomús, boca } \\
\text { del Salado }\end{array}$ & $\begin{array}{l}\text { Félix Álzaga, } \\
\text { Benito } \\
\text { Miguens }\end{array}$ \\
\hline $\begin{array}{l}\text { Francisco } \\
\text { Villarino }\end{array}$ & 52 & $\begin{array}{l}\text { Militar: Comandante } \\
\text { de intanteria; Juez de } \\
\text { Paz; federal } \\
\text { dorreguista }\end{array}$ & Chascomús & $\begin{array}{l}\text { Crámer, } \\
\text { Mendiola, } \\
\text { Posse }\end{array}$ \\
\hline
\end{tabular}

A través de esta información podemos evaluar algunas cuestiones. Por un lado, desde fines de los tiempos virreinales, se fueron conformando redes de comerciantes estrechamente vinculados al poder político. Con la Revolución y la Independencia, el vuelco a la tierra de las élites urbanas dio continuidad a dichas redes, reformulándolas y reconfigurándolas en función del nuevo contexto. La cercanía con el poder y la formación de redes de relaciones personales, familiares y comerciales fueron clave en el proceso de poblamiento al sur del Salado (D'Agostino, 2012: 97; Reguera, 2006: 71). En los datos presentados vemos que los vínculos, tanto con el poder como entre ellos, tuvieron mucha importancia a la hora de adherir a la sublevación. Los casos de los hermanos Ramos Mejía, Álzaga y Campos, Díaz Vélez, Ezeiza y el propio Castelli ilustran esta reconversión de las élites virreinales a través del proceso revolucionario. A la par de la cuestión familiar y relacional, se nos hace destacable la edad de los participantes. Muchos de ellos eran hombres de más de 40 años, con lo cual habían vivido durante su juventud el proceso independentista $\mathrm{y}$, como mostramos previamente, tuvieron participación militar y política en la década del diez. Esto puede entenderse como parte de un proceso formativo de la identidad y el compromiso asumido en defensa de la causa revolucionaria. Además, en el caso de los más jóvenes, generacionalmente pertenecen a familias que también tenían un anclaje político con la Revolución.

Por otro lado, quisiéramos sumar algunos datos que nos permiten mostrar también la inserción que algunos de los cabecillas tenían en el entorno local de la campaña. Benito Miguens, Pedro Castelli y Leonardo Piedrabuena realizaron, a comienzos de la década del treinta, donaciones para construir el templo del pueblo de Dolores (Pirali, 2013: 54). En el mismo partido, para 1835, 
figuran como dueños de casas de comercio o pulperías ${ }^{41}$ dentro del pueblo Crespín Peralta, Juan Mendiburu y Tiburcio Lens. ${ }^{42}$ Mientras que en la zona rural funcionaban este tipo de establecimientos comerciales en las estancias Bella Vista de Álzaga y en La Postrera de Crámer (Pirali, 2013: 57).

\section{Un ejercicio de visualización de redes}

A partir de la información expuesta y de los fundamentos del enfoque de redes de relaciones, a continuación esbozamos la visualización de un gráfico que representa la red de relaciones. Este esquema esta realizado en función de dimensionar la cantidad vínculos. Es decir que Crámer es el sujeto con el que es posible conectar mayor cantidad de sujetos.

\section{Cuadro 1}

\section{Esbozo de red a partir de Ambrosio Crámer}

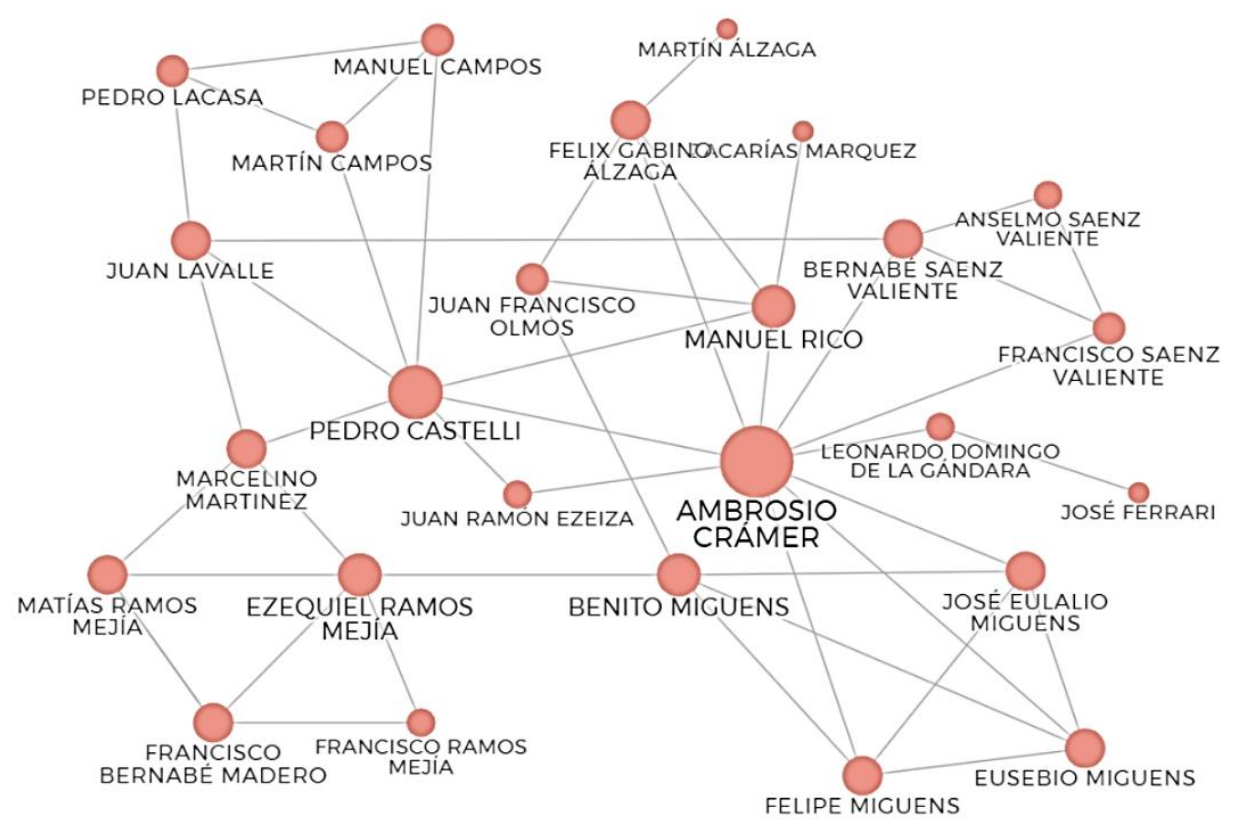

Elaboración propia a partir de la información recopilada

\footnotetext{
${ }^{41}$ Las pulperías y las casas de comercio en el ámbito de la campaña hacia el siglo XIX han sido estudiadas por varios autores. Una de las conclusiones principales radica en entender a estos sitios como espacios de sociabilidad y encuentro (Carrera, 2010; Mayo, 2007).

${ }^{42}$ Los tres fueron participantes del Levantamiento. Lens había sido Juez de Paz de Dolores, mientras que Crispín Peralta actuó como Capitán durante el Levantamiento liderando una de las partidas.
} 
Esto se da a partir de las mensuras que, como comentamos más arriba, realizó para muchos de los líderes de la sublevación. A su vez, incorporamos las relaciones que referimos en el apartado anterior (familiares, vecindad, amistad, armas), como la relación de amistad entre Pedro Castelli y Manuel Campos, así como con Juan Lavalle, $\mathrm{u}$ otro caso es la conexión entre Benito Miguens y Juan Francisco Olmos a partir de haber compartido experiencia miliciana, por citar algunos ejemplos.

En el caso particular de Crámer, además de las mensuras, lo podemos vincular con Manuel Rico a partir de la correspondencia relativa al Levantamiento que se recuperó. ${ }^{43}$ En ellas, Rico desde Dolores escribe indicaciones dirigidas a su subordinado Zacarías Marquez. Algunas de las elocuciones sobre Crámer son:

"Mi querido amigo, no le mando los caballos, porque puede pedir a los Álzagas y demás amigos; pues Crámer me dice que él le dará también caballos. V. ríjase por todo lo que le diga Crámer, pues conozco que es hombre de consejo: me parece muy propio que si en caso se encontrase con alguna gente enemiga siempre evite el tirotearse, pues es mejor buscar los medios de la suavidad que los de romper el fuego...".44

Aquí podemos observar la relevancia de la figura de Crámer por su experticia militar y política. La referencia al consejo también aparece en otra comunicación: “...Esta carta preséntela a Crámer, de quien V. tomará siempre sus consejos y consultará todas sus medidas. Sería muy conveniente que Crámer presenciase su entrevista con Olmos, y que su parecer me lo comunique en el momento". ${ }^{45}$ También en la obra de Carranza cuando comenta acerca de las decisiones militares que llevaron a la derrota en la batalla de Chascomús: "hay verdaderamente extraño que Castelli y su consejero Crámer, que era así mismo el jefe de la vanguardia, militares ambos de línea y hombres de experiencia en la guerra..." (Carranza: 1919: 206). Más allá del contenido de las misivas, son prueba fehaciente del vínculo generado entre estos actores para llevar adelante la sublevación. En la correspondencia aparecen también otros sujetos, como "los Álzagas", a los que se refiere como "amigos". Este vocablo se repite en varias oportunidades:

\footnotetext{
${ }^{43}$ Las cartas fueron publicadas en La Gaceta Mercantil del 12 de noviembre de 1839. AHPBA La Gaceta Mercantil. Buenos Aires 1823-1852. Volumen VIII (1838-1839). Buenos Aires Provincia. Edición digital.

${ }^{44}$ Carta de Rico a Marquez. $1^{\circ}$ de noviembre de 1839, AHPBA La Gaceta Mercantil. Buenos Aires 1823-1852. Volumen VIII (1838-1839). Buenos Aires Provincia. Edición digital, 12 de noviembre de 1839.

${ }^{45}$ Carta de Rico a Marquez, $1^{\circ}$ de noviembre de 1839, AHPBA La Gaceta Mercantil. Buenos Aires 1823-1852. Volumen VIII (1838-1839). Buenos Aires Provincia. Edición digital, 12 de noviembre de 1839.
} 
“En fin con respecto a política déjelo a Cramer, que él de acuerdo con nuestro partidarios en Chascomús lo arreglará, y dígale que me parece muy arreglado cuanto él me dice en su carta en orden a Chascomús, lo mismo que después de tomado este pueblo el dirigirse a Ranchos, y extender nuestra fuerza y vigilancia en dirección al Monte, per de aquel lado de Ranchos, suponiéndome que esto esta conseguido pues nuestros amigos de Chascomús tienen relaciones con muchas personas de prestigio pertenecientes al partido de Ranchos, e invitándolos estoy cierto que no se reusarán a seguirnos. Aguardo hoy a Castelli, López y todos los demás amigos que vienen con grandes tozos de gente...". ${ }^{46}$

Estas comunicaciones de Rico nos iluminan varias cuestiones. En primer lugar, la existencia de otras vías de comunicación entre los sublevados cuando hace referencia a la carta que Crámer le remite sobre la situación de Chascomús. En segundo lugar, la relevancia que le otorga a la amistad y a las "relaciones con personas de prestigio" que se plegarían al Levantamiento. Este elemento nos permite inferir la existencia de relaciones previas que se pusieron en juego en función de la rebelión. La dinámica en la que se llevó adelante la sublevación, expandiéndose por la campaña sur de Buenos Aires, da cuenta de un conocimiento del espacio y de los recursos disponibles para la misma. Crámer, por las características comentadas a lo largo del trabajo, se nos aparece como el sujeto que necesariamente contaba con los recursos, tanto materiales como simbólicos, en relación a sus conocimientos sobre el terreno por su oficio de agrimensor, como para aglutinar la rebelión.

\section{Reflexiones finales}

El ejercicio metodológico que implica el análisis de redes, teniendo en cuenta las consideraciones comentadas al comienzo del trabajo, nos permitió ordenar la información ya recopilada de una manera diferente. Si bien no hemos profundizado en un conocimiento novedoso sobre la temática elegida, pudimos presentar una visualización que conecta a los sujetos. Si tenemos en cuenta que las redes de relaciones son dinámicas y flexibles en función de cambios tanto individuales como sociales, se puede decir que, al calor de la crisis desencadenada a partir del año 1838, que tuvo un impacto profundo en la campaña de Buenos Aires por las decisiones económicas que conllevó, se configuraron un conjunto de redes de relaciones con la finalidad de organizar la sublevación. A partir de la figura de Crámer se comienza a diagramar la red y

\footnotetext{
46 Carta de Rico a Marquez. 3 de noviembre de 1839 a las 12 de la noche, AHPBA La Gaceta Mercantil. Buenos Aires 1823-1852. Volumen VIII (1838-1839). Buenos Aires Provincia. Edición digital, 12 de noviembre de 1839.
} 
establecer los vínculos concretos. Claro que esto no explica ni las motivaciones ni la naturaleza de dichas conexiones. Tomando como punto de partida este primer ejercicio creemos que se puede volver a implementar con un corpus documental mucho más extenso que ahonde en las prácticas económicas, sociales y familiares de los actores intervinientes con la finalidad de explicar cuál era la fundamentación de los vínculos.

\section{Referencias bibliográficas}

Banzato, G., Infesta, M. E. \& Valencia, M. (2018). Expansión de la frontera, tierra pública y formación de las elites terratenientes en la provincia de Buenos Aires, 1780-1880. En M. F. Barcos y J. Troisi Melean (Comps.), Elites rioplatenses del siglo XIX: biografías, representaciones, disidencias y fracasos (pp. 133-168). Facultad de Humanidades y Ciencias de la Educación, Universidad Nacional de La Plata.

Barcos, M. F. \& Lanteri, M. S. (2013). Tierras públicas y construcción del estado en Buenos Aires durante el siglo XIX. Las donaciones ejidales y condicionadas en una visión comparada, Boletin del Instituto de Historia Argentina y Americana «Dr. Emilio Ravignani» (38), 43-77.

Barriera, D. (2006). Un rostro local de la Monarquía Hispánica: Justicia y equipamiento político del territorio al sureste de Charcas, siglos XVI y XVII, Colonial Latin American Historical Review, 15 (4), 377-418.

Bertrand, M. (2000). Los modos relacionales de las élites hispanoamericanas coloniales: Enfoques y posturas. Anuario IEHS, (15), 61-80.

Bragoni, B., \& Mata de López, S. (2007). Militarización e identidades políticas en la revolución rioplatense. Anuario de Estudios Americanos, 64 (1), 221-256.

Carranza, A. (1919). La revolución del 39 en el sud de Buenos Aires. Casa Vaccaro.

Carrera, J. (2010). Pulperos y pulperías rurales bonaerenses: Su influencia en la campaña y los pueblos, 1780-1820 (Tesis doctoral inédita). Universidad Nacional de La Plata. Facultad de Humanidades y Ciencias de la Educación, La Plata. [en línea] https://memoria.fahce.unlp.edu.ar/tesis/te.338/te.338.pdf

Caula, E. (2013). Sociabilidades mercantiles y prácticas comerciales de los mercaderes vascos en el Buenos Aires virreinal. Caravelle, (101), 193-216.

D'Agostino, V. (2007). Enfiteutas, propietarios, agregados y ocupantes en el «nuevo sur»: Los partidos de Arenales y Ayacucho (1823-1860). Mundo Agrario, 7

[en línea]

https://www.mundoagrario.unlp.edu.ar/article/view/v07n14a07

D’Agostino, V. (2012). Expansión de la frontera y ocupación del nuevo Sur: Los partidos de Arenales y Ayacucho, Provincia de Buenos Aires, 1820-1900. Prometeo. 
De Angelis, P. (1837). Colección de obras y documentos relativos a la Historia Antigua y Moderna de las Provincias del Río de la Plata, ilustrados con notas y disertaciones por Pedro De Angelis. Tomo sexto. Imprenta del Estado.

Del Valle, L. C. \& Larrosa, J. M. (2019). Actores y poder en el Cabildo del Buenos Aires, 1776-1810: Una contribución desde el análisis de redes sociales. Revista Brasileira de História, (39) 80, 135-154.

Di Meglio, G. (2013). La participación política popular en la provincia de Buenos Aires, 1820-1890. Un ensayo. En G. Di Meglio y R. Fradkin (Eds.), Hacer política: la participación popular en el siglo XIX rioplatense (pp. 273-303). Prometeo.

Di Meglio, G. (2012). ¡Mueran los salvajes unitarios!: La mazorca y la política en tiempos de Rosas. Sudamericana.

Di Meglio, G. (2006). «Os habeis hecho temibles». La milicia de la ciudad de Buenos Aires y la política entre las invasiones inglesas y el fin del proceso revolucionario, 1806-1820. Tiempos de América, (13), 151-166.

Domínguez Arribas, J. (2003). El enemigo unitario en el discurso rosista (18291852). Anuario de Estudios Americanos, 60 (2), 557-579.

Domínguez Soler, S. (2006). La familia Campos en la historia y la genealogía (2. ed). Dunken.

Echeverría, E. (1854). Apéndice. Documentos referentes a la insurrección del sud de Buenos Aires. Copiados de La Gaceta Mercantil. Periódico Oficial de Rosas. En Insurrección del Sud de Buenos Aires en octubre de 1839. Poema con notas y documentos. Imprenta Constitución.

Flores, R. D. (2010). Familias británicas en la Sociedad Rural Argentina, 18661912. Épocas. Revista de Historia, (3), 95-132.

Fradkin, R. (2006). La historia de una montonera: Bandolerismo y caudillismo en Buenos Aires, 1826. Siglo Veintiuno Editores.

Fradkin, R. (2008). ¡Fusilaron a Dorrego! O cómo un alzamiento rural cambió el rumbo de la historia. Sudamericana.

Fradkin, R. \& Gelman, J. (2008). Dossier Actores intermedios y políticas en el mundo rural del siglo XIX: Presentación. Anuario IEHS, (23), 147-223.

Garavaglia, J. C. (2007). Construir el estado, inventar la nación: El Río de la Plata, siglos XVIII-XIX. Prometeo.

Gelman, J. (1996). De mercachifle a gran comerciante: Los caminos del ascenso en el Río de la Plata colonial. La Rábida: Universidad Internacional de Andalucía, Sede Iberoamericana de la Rábida - Universidad Nacional de Buenos Aires.

Gelman, J. (2009). Rosas bajo fuego: Los franceses, Lavalle y la rebelión de los estancieros. Sudamericana. 
Gelman, J. (2010). Rosas estanciero: Gobierno y expansión ganadera. Capital Intelectual.

Gelman, J. \& Santilli, D. (2004). Expansión ganadera y diferencias regionales. La campaña de Buenos Aires en 1839. En R. Fradkin \& J. C. Garavaglia (Eds.), En busca de un tiempo perdido: La economía de Buenos Aires en el país de la abundancia, 1750-1865, Prometeo, pp. 235-286.

Gelman, J. \& Schroeder, M. I. (2003). Juan Manuel de Rosas contra los estancieros: Los embargos a los unitarios de la campaña de Buenos Aires, Hispanic American Histórical Review, 83 (3), pp. 487-520.

Germinario, C. (2017). Las transformaciones en la conformación jurídicoterritorial de la campaña bonaerense sur en la coyuntura de crisis del régimen rosista: Dolores (1838-1841). En M. A. Vaccaroni (Comp.), Estudios y proyectos en curso de jóvenes investigadores del Centro de Estudios Históricos, Universidad Nacional de Mar del Plata, pp. 32-43.

Germinario, C. (2020). Prácticas políticas durante la crisis del rosismo en espacios de nueva ocupación: Dolores y Monsalvo (1838-1841), en AA. VV. Estudios y proyectos en curso de jóvenes investigadores. IV Jornadas de Jóvenes Investigadores del Centro de Estudios Históricos, Universidad Nacional de Mar del Plata, pp. 99-116.

González Bernaldo de Quirós, P. (1987). El levantamiento de 1829: El imaginario social y sus implicancias políticas en un conflicto rural. Anuario IEHS, (2), 135176.

Halperin Donghi, T. (2010). De la revolución de independencia a la Confederación rosita (3. ed., 2. reimpr). Paidós.

Hespanha, A. M. (1989). Vísperas del Leviatán. Institución y Poder político. Taurus.

Hespanha, A. M. (1996). Una nueva historia política e institucional. Revista mexicana de ciencias políticas y sociales, 41 (166), 9-45.

Hora, R. \& Losada, L. (2015). Una familia de la elite argentina: Los Senillosa, 18101930. Prometeo.

Imízcoz Beunza, J. M. (2009). Las redes sociales de las élites. Conceptos, fuentes y aplicaciones. En E. Soria Mesa; J. J. Bravo Caro \& J. M. Delgado Barrado (Eds.). Las élites en la época moderna: La monarquía española. Vol. 1 Nuevas perspectivas (pp. 77-111). Universidad de Córdoba, Servicio de Publicaciones.

Irigoin, M. \& Schmit, R. (2003). La desintegración de la economía colonial. Comercio, moneda en el interior del espacio colonial (1800-1860). Biblos.

Kloster, M. (2019). Reflexiones sobre la actividad diplomática de la Confederación de Provincias Argentinas. El caso del Bloqueo Francés (1838- 
1840). Nuevo mundo mundos nuevos. [en línea] https://doi.org/10.4000/nuevomundo.78434

Lacasa, P. (1858). Vida militar y política del general argentino Don Juan Lavalle. Imprenta Americana.

Lanteri, M. S. \& Pedrotta, V. (2015). La frontera sur de Buenos Aires en la larga duración. Una perspectiva multidisciplinar. Asociación Amigos Archivo Histórico de la Provincia de Buenos Aires.

Levene, R. (1940). Historia de la Provincia de Buenos Aires y formación de sus pueblos (Vols. 1-2). Archivo Histórico de la Provincia de Buenos Aires.

Mascioli, A. (2002). Caminos de acceso al usufructo y propiedad legal de la tierra en la frontera bonaerense. Dolores, 1798-1860. Quinto Sol, (6), 69-106.

Mayo, C. (Ed.) (2007). Mostradores, clientes, y fiado: Fuentes para el estudio de las pulperías de Buenos Aires y la pampa, siglo XIX. Ediciones Suárez.

Mazzanti, D.; Canedo, M.; Parín, C.; Mateo, J. \& Reynoso, D. (1991). Capítulo primero: El poblamiento inicial de la región. En A. Álvarez et al. Mar del Plata. Una historia urbana (pp. 13-43). Fundación Banco Boston.

Molina, E. (2011). Sociabilidad y redes político-intelectuales: Algunos casos entre 1800 y 1852. Cuadernos del CILHA, 12 (1), 19-54.

Morelli, F. (2007). Entre el antiguo y el nuevo régimen. La historia política hispanoamericana del siglo XIX. Historia Crítica, (33), 122-155.

Moutoukias, Z. (1996). Negocios y redes sociales: Modelo interpretativo a partir de un caso rioplatense (Siglo XVIII). Caravelle, (67), 37-55.

Moutoukias, Z. (2000). Gobierno y sociedad en el Tucumán colonial, 1550-1800. En E. Tandeter (Dir.). Nueva Historia Argentina. La sociedad colonial: Tomo 2 (pp. 355-415). Sudamericana.

Moutoukias, Z. (2015). Dependencias temporales y cambios institucionales en la América hispánica a fines del siglo XVIII e inicios del siglo XIX. Historia Crítica, (58), 157-178.

Moutoukias, Z. (2017). Instituciones, redes personales y cambio institucional. Una reflexión a partir de la noción de convención. En M. Bertrand; F. Andújar Castillo \& Th. Glesener (Eds.), Gobernar y reformar la monarquía: Los agentes políticos y administrativos en España y América (siglos XVI-XIX) (pp. 95-122). Albatros.

Muzzio, J. (1920). Diccionario histórico y biográfico de la República Argentina (Vols. 1-2). Librería «La Facultad» de Juan Roldán.

Palti, E. (2007). El tiempo de la política: El siglo XIX reconsiderado. Siglo Veintiuno Editores. 
Parrado, E. (2020). Milicias provinciales y ejércitos nacionales: Las dimensiones simbólicas en la construcción de las identidades políticas en Tucumán y el norte argentino durante la guerra contra la Confederación Perú-boliviana (1837-1839). Claves. Revista de Historia, 6 (11), 1-24.

Paz, G. (2010). La vida política. En J. Gelman (Ed.), Argentina. La construcción nacional. 1830-1880, Vol. II, Taurus, Fundación Mapfre, pp. 29-80.

Pirali, J. C. (2013). Origen y evolución de Dolores: Reseña histórica de un pueblo y partido de la provincia de Buenos Aires. Dunken.

Prado y Rojas, A. (1877). Leyes y decretos promulgados en la Provincia de Buenos Aires desde 1810 a 1876. Tomo III: 1824-1852. Imprenta del Mercurio.

Ratto, S. (2015). Redes políticas en la frontera bonaerense (1836-1873). Crónica de un final anunciado. UNQ.

Reguera, A. (2016). La Comandancia general de Juan Manuel de Rosas de la División Izquierda de la Expedición al Desierto de 1833. Lazos personales, relaciones de mando y subordinación en el proceso de ocupación territorial de la pampa bonaerense. Revista TEFROS, 14 (1), 76-120.

Reguera, A. (2006). Entre la ley y el azar. La trama vincular del mundo políticoempresarial de la frontera sur pampeana en el siglo XIX. Prohistoria, (10), 47-72.

Rosa, J. M (1962). Historia Argentina. Unitarios y Federales (1826-1841), Tomo IV. Editorial Oriente.

Sábato, H. \& Lettieri, A. R. (Eds.). (2003). La vida política en la Argentina del siglo XIX: Armas, votos y voces (1. ed). Fondo de Cultura Económica.

Saldías, A. (1892). Historia de la Confederación Argentina. La época de Rozas (Vol. 3). Felix Lajouane Editor.

Salvá, V. (1847). Nuevo diccionario de la lengua castellana. Que comprende la última edición integra, muy rectificada y mejorada, del publicado por la Academia Española, y unas veinte $y$ seis mil voces, acepciones, frases y locuciones, entre ellas muchas americanas, añadidas por Don Vicente Salvá. Librería de Don Vicente Salvá. Segunda Edición.

Santilli, D. (2003). Representación gráfica de redes sociales. Un método de obtención y un ejemplo histórico. Mundo Agrario, 3 (6), 1-21.

Socolow, S. (1991). Los mercaderes del Buenos Aires virreinal: Familia y comercio. Ediciones de la Flor.

Truchuelo García, S. \& Reitano, E. (Eds.) (2017). Las fronteras en el mundo atlántico (siglos XVI-XIX). Facultad de Humanidades y Ciencias de la Educación, Universidad Nacional de La Plata. [en línea] http://libros.fahce.unlp.edu.ar/index.php/libros/catalog/book/85 
Prohistoria, Año XXIV, 36, dic. 2021, ISSN 1851-9504

Zubizarreta, I. (2015). Las logias antirrosistas: Análisis sobre dos agrupaciones secretas que intentaron derrocar a Juan Manuel de Rosas, 1835-1840, Historia Crítica, (55), pp. 19-43. 